\title{
Functional response of Rhynocoris kumarii (Hemiptera: Reduviidae) to different population densities of Phenacoccus solenopsis (Hemiptera: Pseudococcidae) recorded in the laboratory
}

\author{
KITHERIAN SAHAYARAJ ${ }^{1}$, VIVEK KUMAR ${ }^{2}$ and PASCO B. AVERY ${ }^{3}$ \\ ${ }^{1}$ Crop Protection Research Centre, St. Xavier’s College, Palayamkottai 627 002, Tamil Nadu, India; e-mail: ksraj48@gmail.com \\ ${ }^{2}$ Mid-Florida Research and Education Center, University of Florida, 2725 South Binion Road, Apopka, FL 32703, USA; \\ e-mail: vivekiari@ufl.edu \\ ${ }^{3}$ Indian River Research and Education Center, University of Florida, 2199 South Rock Road, Fort Pierce, FL 34945, USA; \\ e-mail: pbavery@ufl.edu
}

Key words. Hemiptera, Reduviidae, Rhynocoris kumarii, Pseudococcidae, Phenacoccus solenopsis, bioefficacy, functional response, reduviid predator, cotton mealybug, biological control

\begin{abstract}
Cotton mealy bug, Phenacoccus solenopsis Tinsley, a polyphagous pest is a serious threat to cotton production in several parts of Southeast Asia. Lack of an effective predator against this pest has resulted in the use of intensive chemical-based management strategies. Studies were carried out under laboratory conditions to determine the functional response of the adults and nymphs of a generalist reduviid predator, Rhynocoris kumarii Ambrose and Livingston, to different population densities $(1,2,4,6,8$ and 10$)$ of $P$. solenopsis. Males, females and nymphs of this reduviid showed a type II functional response. There was no significant difference in the attack rate of male and female $R$. kumarii; however, prey-handling times of the sexes differed significantly. Of the sexes, males were more aggressive and killed a significantly higher number of third instar mealy bugs than females and had a Holling type II curvilinear functional response. Functional responses of the nymphal instars (third, fourth and fifth) and adults (female and male) of $R$. kumarii were more pronounced than those of the first and second nymphal instars. Results indicate that the nymphal instars of $R$. kumarii can be more effective at regulating $P$. solenepsis than adult reduviids. The findings of this study are important as they demonstrate the considerable potential of R. kumarii for controlling the cotton mealy bug, but now need to be evaluated under greenhouse and field conditions.
\end{abstract}

\section{INTRODUCTION}

Phenacoccus solenopsis Tinsley (Hemiptera: Sternorrhyncha: Coccoidea: Pseudococcidae) is reported at 35 localities in various ecological zones of the globe (Hodgson et al., 2008; Ben-Dov et al., 2009; Nagrare et al., 2009; Wang et al., 2009). In Asia, widespread damage of cotton due to feeding by this invasive pest was first reported in Pakistan in 2006 (Zaka et al., 2006). Since then there has been an increase in the population of this pest on cotton and other hosts, which has threatened the economic production of many crops in the region. Worldwide, this mealy bug damages more than 180 plant taxa in 52 families (BenDov et al., 2009). Damage due to P. solenopsis may result in distorted, bushy shoots, crinkled and/or twisted bunches of leaves, reduced plant vigour, early crop senescence and stunting (Nagrare et al., 2011). In addition, deformation resulting from severe infestations plus chlorosis due to toxic saliva may kill plants (Tanwar et al., 2007). Recently, it has become the most serious pest threatening cotton cultivation in nine major cotton-growing states of India, which include Andhra Pradesh, Gujarat, Haryana, Karnataka, Madhya Pradesh, Maharashtra, Punjab, Rajasthan and Tamil Nadu (Nagrare et al., 2009; Vennila et al., 2010). In some regions, problems due to this pest have been so severe that the Central Institute for Cotton Research (India) formed a task force for managing this pest species (Vennila et al., 2010).

Due to the recent invasion of $P$. solenopsis in India, there is a lack of information about effective biological control of this pest in the region. Thus, uses of synthetic chemicals are considered the primary mode for its control. However, management of this pest using chemical insecticides is also challenging and sometimes ineffective, because there is a waxy deposit on the dorsal surface of $P$. solenopsis that protects it against the active ingredients of insecticides (Nagrare et al., 2011). Thus, it is urgent that an effective biocontrol agent, which is readily available to cotton growers, is found so that the considerable crop losses due to this pest can be reduced.

In a recent study conducted in Tandojam, Pakistan by Solangi et al. (2012) it was found that it was found that the ladybird beetle, Cryptolaemus montrouzieri Mulsant is effective at controlling $P$. solenopsis under laboratory conditions. However, the efficacy of this predator at a commercial scale, still needs to be assessed under greenhouse and field conditions. Another natural enemy observed in the cotton growing regions of southern India, often in high numbers, is the generalist reduviid predator, Rhynocoris kumarii Ambrose \& Livingston (Hemiptera: Reduviidae). The adults and nymphs of this reduviid feed on a variety of pests, such as Spodoptera litura Fabricius (Sahayaraj \& Sivakumar, 1995), Aphis craccivora (Koch) (Sahayaraj \& 
Asha, 2010), Helicoverpa armigera (Hubner) and Anomis flava (Fabricius) (Ambrose, 2000); young nymphs of some other lepidopterous pests (Claver \& Ambrose, 2001a; Ambrose \& Claver, 2001) and Dysdercus cingulatus Distant (Claver \& Ambrose, 2001b) on cotton. In addition, after the use of conventional insecticides, these predators were observed foraging on cotton plants (Ambrose et al., 2008). In 2011, we observed this predator feeding on cotton mealy bugs under laboratory as well as screen house conditions (K.S., pers. observ.); however, at that time there was insufficient data to warrant it being considered as a potential biocontrol agent of $P$. solenopsis. Thus, in the current study we evaluated the biocontrol efficacy of the different predatory life-stages of $R$. kumarii against $P$. solenopsis. If this predator demonstrates efficacy against the mealybug, then the next stage of the augmentation process would be to mass rear R. kumarii for release in greenhouses and the field release tests (Ambrose \& Rani, 1991; Claver et al., 1996). This integrated management strategy if effective, could help reduce the extensive dependence of cotton production on synthetic insecticides.

In the field, prey density can affect the efficacy of a biocontrol agent. Thus, it is important to determine the prey density at which a predator is most efficient in regulating pest populations, which may help determine the appropriate time for mass release. The potential biocontrol efficacy of a candidate agent can be extrapolated by quantifying its functional response, which can serve as a predictor of attainable top-down, density-dependent regulation of a given species of pest (Murdoch \& Oaten, 1975). Although in the past some studies have investigated the functional response of R. kumarii to population densities of a variety of pests (Ambrose et al., 2008; Sahayaraj \& Asha, 2010), there are none involving hemipteran cotton pests, particularly $P$. solenopsis. Thus, the specific objectives of this study were to: (1) evaluate the efficacy of the life stages of $R$. kumarii as biocontrol agents of different prey densities of $P$. solenopsis and (2) compare the functional responses of these life stages under laboratory conditions.

\section{MATERIAL AND METHODS}

\section{Test insects}

Colonies of $R$. kumarii and P. solenopsis were established from adults and nymphs collected from cotton fields located at Killikulam Agricultural College and Research Institute, in Vallanadu ( $8^{\circ} 46^{\prime} \mathrm{N}$ latitude and $77^{\circ} 42^{\prime} \mathrm{E}$ longitude), Tamil Nadu, India. They were maintained in a rearing room at a constant temperature of $28 \pm 2{ }^{\circ} \mathrm{C}, 60-70 \%$ relative humidity under a $11 \mathrm{~h}$ photophase in transparent plastic containers $(7.0-\mathrm{cm}$ diameter and $16.2-\mathrm{cm}$ high). Reduviids were fed immature rice moth nymphs (Corcyra cephalonica Stainton) and life stages of $P$. solenopsis on alternate days for one generation. $P$. solenopsis used in these studies were reared on 30-60 day old Srivilliputtur 2 (SVP2 variety) cotton plants inside cages under a screen house.

\section{Experimental arena}

Each experimental arena consisted of a Petri dish (9 cm diam) with a ventilation hole in the polystyrene lid and lined with a moist layer of cotton wool. Leaf discs were cut from leaves of healthy, young, vigorous cotton plants (variety SVP2) that were free of arthropod pests. Leaf discs $\left(16 \mathrm{~cm}^{2}\right)$ were cut with scissors from the center of the blade of detached cotton leaves beginning near the intersection between the petiole and the edge of the leaf. Leaf discs were placed with the abaxial surface on the layer of cotton wool in the arenas. Different numbers of third instar mealy bugs, either $1,2,4,6,8$, or 10 , were gently placed on the leaf discs in separate Petri dishes, and left undisturbed to settle for $1 \mathrm{~h}$. Once the mealy bugs had settled on the cotton leaf discs, a single (12 h pre-starved) nymph (first, second, third, fourth or fifth instar), or male or female adult of $R$. kumarii was introduced into each dish. The number of prey killed by each of different life stages of R. kumarii was recorded every $24 \mathrm{~h}$ for three days. To maintain the same number of prey in each dish, dead prey was replaced with similar aged prey every $24 \mathrm{~h}$. Each treatment in terms of a particular life stage of predator and number of prey was replicated 10 times.

\section{Functional response and data analysis}

Holling's Disc equation (Holling, 1965) was used to describe the functional response of $R$. kumarii as follows:

$$
\mathrm{y}=\mathrm{a}(\mathrm{Tt}-\mathrm{by}) \mathrm{x}
$$

where, $x=$ number of prey offered; $y=$ total number of prey killed in given period of time; $\mathrm{a}=$ rate of discovery per unit of searching time $[(\mathrm{y} / \mathrm{x}) / \mathrm{Ts}] ; \mathrm{Ts}=$ time spent by the predator searching for prey each day; $b=$ time the predator spent handling each prey individual $(\mathrm{Tt} / \mathrm{k}) ; \mathrm{Tt}=$ total time in days prey were exposed to the predator, $\mathrm{k}=$ maximum number of prey killed in a given period of time; prey consumption ratio $(y / x)=$ the ratio of the number of prey offered (x) and killed or consumed by a predator (y).

Regression and correlation analyses were used to determine the relationship between prey population density and number of prey consumed, and the searching time of the different stages of $R$. $k u$ marii using the SPSS program (version 11.5, 2006). To determine the number of prey killed, handling time, time spent searching each day, days spent searching or total searching time for prey and maximum number of prey killed by different life-stages of $R$. kumarii, all data were analyzed using the SPSS program (version 20.0, 2012). If necessary, data were normalized using square root transformation of $X+0.25$. Data were analyzed using a oneway ANOVA and differences amongst the treatment means were tested using Tukey's HSD test at $\alpha=0.05$. Significant differences in the mean number of prey killed, handling time, total time spent searching for prey, rate of discovery, and maximum number of prey killed by both males and females were compared using a t-test $(p<0.05)$. The non-transformed mean values are presented in Table 1.

\section{RESULTS AND DISCUSSION}

A type II functional response curve fits best the parameters when considering the numbers of prey offered and consumed in a day by the different nymphal instars (Fig. 1) and adults (Fig. 2) of R. kumarii. All of the life stages of $R$. kumarii tested showed similar functional responses; the number of prey consumed per predator increased as the prey density offered increased (Fig. 1). Mean number of prey killed per unit time by the first, second and third instars gradually increased and then stabilized with the fourth and fifth instar nymphs killing similar numbers of prey (Table 1). Adult males consumed significantly higher numbers of prey than females (Table 1). In general, fifth instar predators consumed the greatest number of prey per $24 \mathrm{~h}$ and the numbers consumed by all instars increased 


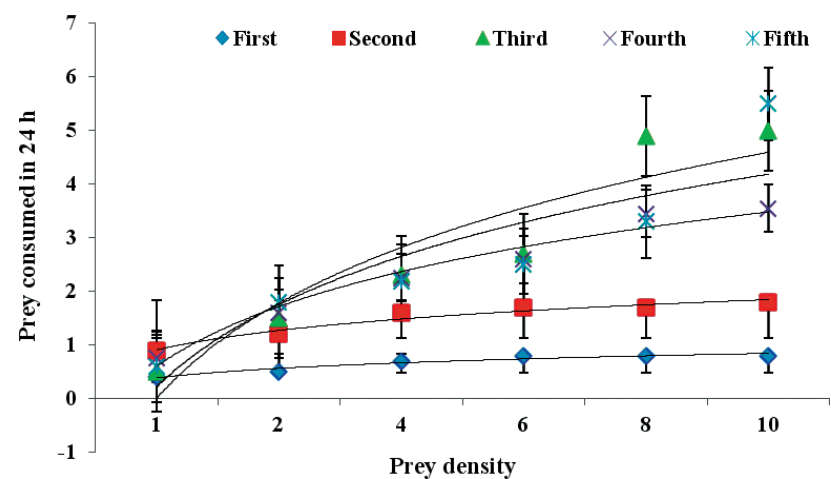

Fig. 1. Mean number of prey killed by nymphs (first, second, third, fourth and fifth instars) of Rhynocoris kumarii in $24 \mathrm{~h}$ as a function of the population density of third instar mealy bugs.

with increasing densities of prey (Fig. 1). This was further confirmed by the correlation obtained for this instar $(\mathrm{y}=$ $0.3356+0.4479 \mathrm{x}, r=0.9443)$. Similar relationships were also recorded for the first, second, third, and fourth instar $(\mathrm{y}=0.4345+0.0449 \mathrm{x}, r=0.8949 ; \mathrm{y}=1.0143+0.0906 \mathrm{x}, r$ $=0.8922 ; \mathrm{y}=0.2012+0.5060 \mathrm{x}, r=0.9719$ and $\mathrm{y}=0.8138$ $+0.3005 \mathrm{x}, r=0.9697)$, respectively, and adult males (y $=0.4742+0.1791 \mathrm{x}, r=0.9440)$ and females $(\mathrm{y}=0.7079$ $+0.0468 \mathrm{x}, r=0.9121)$. In other species of Rhynocoris, similar functional responses to different species of pest are recorded for $R$. fuscipes (Fab.) (Ambrose \& Claver, 1997; Claver \& Ambrose, 2002), R. longifrons Stål (Sahayaraj et al., 2012) and R. kumarii (Sahayaraj \& Asha, 2010). However, in contrast to previous studies, we recorded an unexpected saturation $(>80 \%)$ in the predation rate of first instar of $R$. kumarii at a prey population density of 6 mealy bugs, probably due to their small size and consequent con-

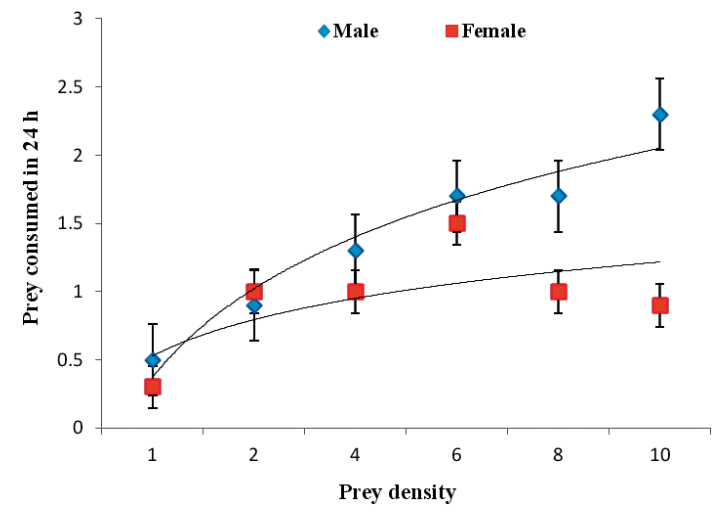

Fig. 2. Mean number of prey killed by adults (male and female) of Rhynocoris kumarii in $24 \mathrm{~h}$ as a function of the population density of third instar mealy bugs.

sumption capacity. In addition, the overall predation rate was lower for adults than nymphs because adults do not successfully attack small prey (Sahayaraj \& Asha, 2010; Sahayaraj et al., 2012).

Over a $24 \mathrm{~h}$ period the third instar of $R$. kumarii was found to be most aggressive and consumed 55\% of the mealy bugs offered compared with $55 \%$ by the fourth, $51 \%$ by the fifth, $29 \%$ by the second and $13 \%$ by the first instar. During the same period, male reduviids consumed a higher percentage of $P$. solenopsis $(27 \%)$ than the females $(20 \%)$. These results indicate that the later instars (third, fourth and fifth) of $R$. kumarii are more effective in regulating $P$. solenopsis populations and therefore their potential as biological control agents of the cotton mealy bug need to be evaluated under greenhouse conditions. The low predation rates recorded for first and second-instars and adults (male and female) of $R$. kumarii were most likely due to

TABLE 1. Functional responses of the different life stages of Rhynocoris kumarii to different population densities of third instar Phenacoccus solenopsis.

\begin{tabular}{|c|c|c|c|c|c|}
\hline \multirow[b]{2}{*}{ Life stages } & \multicolumn{5}{|c|}{ Holling's Disc equation parameters } \\
\hline & $\begin{array}{l}\text { Mean number } \\
\text { of prey killed (y) }\end{array}$ & $\begin{array}{l}\text { Handling time } \\
\qquad(\mathrm{b}=\mathrm{Tt} / \mathrm{k})\end{array}$ & $\begin{array}{l}\text { Total time spent } \\
\text { searching for prey } \\
(\mathrm{Ts}=\mathrm{Tt}-\mathrm{by})\end{array}$ & $\begin{array}{c}\text { Rate of discovery } \\
{[\mathrm{a}=(\mathrm{y} / \mathrm{x}) / \mathrm{Ts}]}\end{array}$ & Maximum y (k) \\
\hline $1^{\text {st }}$ instar & $0.67 \pm 0.01 \mathrm{a}$ & $3.75 \pm 0.44 \mathrm{a}$ & $0.49 \pm 0.19 \mathrm{a}$ & $0.38 \pm 0.11 \mathrm{a}$ & $0.80 \pm 0.33 \mathrm{a}$ \\
\hline $2^{\text {nd }}$ instar & $1.48 \pm 0.21 b$ & $1.66 \pm 0.22 b$ & $0.55 \pm 0.11 \mathrm{ab}$ & $0.50 \pm 0.07 \mathrm{ab}$ & $1.80 \pm 0.66 b$ \\
\hline $3^{\text {rd }}$ instar & $2.82 \pm 0.33 \mathrm{~d}$ & $0.60 \pm 0.32 c$ & $1.31 \pm 0.34 \mathrm{c}$ & $0.59 \pm 0.01 b c$ & $5.00 \pm 0.76 c$ \\
\hline $4^{\text {th }}$ instar & $2.65 \pm 0.55 \mathrm{~cd}$ & $0.57 \pm 0.21 \mathrm{~cd}$ & $1.49 \pm 0.31 \mathrm{~cd}$ & $1.59 \pm 0.23 \mathrm{~d}$ & $5.25 \pm 0.55 \mathrm{~cd}$ \\
\hline $5^{\text {th }}$ instar & $2.65 \pm 0.52 \mathrm{~cd}$ & $0.54 \pm 0.11 \mathrm{cde}$ & $1.57 \pm 0.33 \mathrm{cde}$ & $0.87 \pm 0.39 \mathrm{~cd}$ & $5.50 \pm 0.76 \mathrm{cde}$ \\
\hline \multirow[t]{3}{*}{ Statistical analysis } & $\mathrm{df}=4,58$ & $\mathrm{df}=4,59$ & $\mathrm{df}=4,55$ & $\mathrm{df}=4,51$ & $\mathrm{df}=4,56$ \\
\hline & $F=2.872$ & $F=2.811$ & $F=3.99$ & $F=3.230$ & $F=2.876$ \\
\hline & $p<0.0056$ & $p<0.0533$ & $p<0.0005$ & $p<0.0513$ & $p<0.0059$ \\
\hline Male & $1.40 \pm 0.32 \mathrm{a}$ & $1.30 \pm 0.13 \mathrm{a}$ & $1.18 \pm 0.41 \mathrm{a}$ & $1.25 \pm 0.07 \mathrm{a}$ & $2.30 \pm 0.41 \mathrm{a}$ \\
\hline Female & $1.06 \pm 0.33 b$ & $2.00 \pm 0.41 b$ & $0.88 \pm 0.09 b$ & $0.41 \pm 0.01 b$ & $1.50 \pm 0.23 b$ \\
\hline Statistical analysis & $\begin{array}{l}t=2.072 \\
p=0.05\end{array}$ & $\begin{array}{c}t=6.35 \\
p=0.00143\end{array}$ & $\begin{array}{c}t=6.35 \\
p=0.00143\end{array}$ & $\begin{array}{c}t=4.891 \\
p=0.00451\end{array}$ & $\begin{array}{c}t=6.0 \\
p=0.00020\end{array}$ \\
\hline
\end{tabular}

Means within a column followed by a different letter differ significantly (Tukey's test and t-test; $p<0.05$ ). Functional response described by Holling "disc" equation: $\mathrm{y}=\mathrm{a}(\mathrm{Tt}-\mathrm{by}) \mathrm{x}$ where: $\mathrm{x}=$ number of prey offered; $\mathrm{y}=$ total number of prey killed in given period of time; $a=$ rate of discovery per unit of searching time $[(y / x) / T s] ; b=$ time spent handling each prey by the predator $(\mathrm{Tt} / \mathrm{k})$; where: $\mathrm{Tt}=$ total time in days the prey were exposed to the predator, $\mathrm{k}=$ maximum number of prey eaten in a given period of time. Total time spent searching for prey $\mathrm{Ts}=\mathrm{Tt}$-by where: $\mathrm{Ts}=$ time spent by the predator searching for prey each day; $\mathrm{Tt}=$ total time in days the prey were exposed to the predator. Rate of discovery $a=(y / x) / T s$ where: prey consumption ratio $(y / x)=$ the ratio between number of prey offered (x) and number of prey killed and or consumed by a predator $(\mathrm{y})$; Ts = time spent by the predator searching for prey each day. 
their low mobility, i.e., attack rates and longer prey handling times (Table 1). This is understandable because the first and second instars are small, and adults are large and may have difficulty finding and/or capturing small mealy bugs. A similar observation was reported by Ambrose \& Sahayaraj (1993), who found that the predatory rate of adult Allaeocranum quadrisignatum Reuter fed first and second instars of $D$. cingulatus was less than that of the second, third, fourth and fifth instars of this predator.

The time required for capturing, paralyzing and feeding on prey is called the handling time, and the total time in days that prey are exposed to the predator determines the maximum number eaten. In general, the handling time decreased with increase in instar. This result may be due to larger predators that need more nutrients and energy to maintain their metabolism; consequently they consume a higher number of prey (Table 1). Prior to this study, similar observations were reported by Sahayaraj (2012) for other reduviid predators. However, in the present study, first instar and adult females of $R$. kumarii at high prey population densities (8 and 10 prey/dish), killed $15-30 \%$ of prey without consuming them, i.e. superfluous killing and/or partial prey consumption. This feeding characteristic of $R$. kumarii has also been observed in other predators, such as Macrolophus pygmaeus Wagner (Fantinou et al., 2008, 2009) and $R$. longifrons (Sahayaraj et al., 2012).

In the present study, the prey consumption ratio gradually decreased with increase in prey population density (Table 1). Sahayaraj (1991) reported that reduviid predators generally spend less time searching for prey, which may cause a decline in the attack ratio until hunger is re-established. Moreover, the attack rate of predators is governed by the rate of prey encounter, probability that the prey will be attacked when encountered and probability that an attack will result in prey capture and subsequent consumption (Getty \& Pulliam, 1991; Sahayaraj \& Asha, 2010).

Searching time decreased as prey density increased (more encounters with prey per unit time) and increased as the predator increased in size (up to the fourth instars). It is likely that it is more difficult for the older instars to find small mealy bugs. In addition, adult females search for prey more quickly than males and spent less time handling prey. This indicates that female $R$. kumarii ate more prey initially, probably to meet the requirement for energy to mature their eggs. There were negative correlations between time spent searching and prey density for the different nymphal stages of $R$. kumarii (first instar: $r=-0.5983$; second instar: $r=-0.7154$; third instar: $r=-0.6594$ and fifth instar: $r$ $=-0.0098)$; adult males $(r=-0.6217)$ and adult females $(r$ $=-0.621)$. The only positive correlation $(r=0.7071)$ was recorded for the fourth instar, which is indicative of the aggressiveness of this instar. Predator efficiency depends upon searching ability with those that spend more time searching for prey usually capturing, killing or consuming most prey. For instance, adult male reduviids spent more time searching for mealy bugs, handled them very quickly and therefore consumed a higher number than females.
This has also been recorded by Sahayaraj \& Asha (2010) and Sahayaraj et al. (2012) for other reduviid predators.

The rate of discovery of prey by first instar nymphs was significantly lower than that of third, fourth and fifth instar nymphs. Females spent less time finding prey in a $24 \mathrm{~h}$ period, but consumed less prey than males. We hypothesized that males may need more energy to produce spermathecae and therefore consume more prey by spending more time searching, immediately after eclosion. Handling time decreased as prey population density increased for both nymphs and adults of $R$. kumarii. However, although the handling time of first instar nymphs was high, it decreased when they moulted to the next stadium (Table 1). In addition, first instars nymphs consumed few mealy bugs. A low handling time was recorded for the third, fourth and fifth nymphal instars and they consumed more prey during their lives. However, both males and females did not have a low handling time and the time they spent resting after handling prey was longer at low than at high prey population densities. In addition, male adult predators spent significantly less time handling $P$. solenopis than females (Table 1). This finding differs from that recorded for other reduviid species Cosmoclopius nigroannulatus Stål (da Rocha \& Redaelli, 2004) and $R$. longifrons (Sahayaraj et al., 2012). The short handling time of females is reflected in a slower consumption rate, which results in a semi-linear curve rather than a curve that reaches an asymptote at a population density of 10 prey (Fig. 1). Abrams (1990) indicated that a short handling time and slow consumption rate are behavioural and/or physiological features of predators.

The maximum number of prey eaten was recorded at the highest population densities of prey provided (Table $1)$. When high numbers of prey were provided the predator spent less time searching and more time attacking and consuming prey. The maximum number of prey eaten (or $\mathrm{k}$ value) for first, second, third, fourth, fifth instar nymphs, male and female adults was $0.8,1.8,5.0,5.3,5.5 ., 2.3$ and 0.9 , respectively, at the highest prey population density provided. When $R$. kumarii fourth nymphal instar fed on A. craccivora, the " $\mathrm{k}$ " value was restricted to 75.3 at an allotted density of 85 aphids (Sahayaraj \& Asha, 2010). Similarly, $R$. longifrons adults (male and female) only consumed five $P$. solenopsis when provided with 10 prey (Sahayaraj et al., 2012).

In the current study, the potential of $R$. kumarii as a biocontrol agent of a pest of cotton, $P$. solenopsis was evaluated under laboratory conditions. Males, females and nymphs of the reduviid $R$. kumarii showed a type II functional response when provided with different population densities of $P$. solenopsis. These results indicate that the nymphs of $R$. kumarii, especially the third, fourth and fifth instars, are more effective biocontrol agents of $P$. solenopsis than the adults. Of the sexes, males are more aggressive predators in that they killed significantly more mealy bugs than females. Further studies are needed on the biocontrol potential of this reduviid predator for controlling $P$. solenopsis under controlled greenhouse and open field condi- 
tions before it is utilized in either innundative or augmentative release programs for managing this mealy bug pest.

ACKNOWLEDGEMENTS. The senior author is grateful to MEF, New Delhi (Ref. no. 23-1/2008-RE) for their financial assistance, and would like to thank S. Sivakumar for his technical assistance. The authors are thankful to the management of St. Xavier's College (Autonomous), Palayamkottai for providing the necessary laboratory facilities and encouragement to complete this project.

\section{REFERENCES}

AвRAms P.A. 1990: The effects of adaptive behavior on the type-II functional response. - Ecology 71: 877-885.

Ambrose D.P. 2000: Suppression of Helicoverpa armigera (Hubner) and Anomis flava (Fabricius) infesting okra by the reduviid predator Rhynocoris kumarii Ambrose and Livingstone in field cages. - Pest Manag. Hortic. Ecosyst. 6: 32-35.

Ambrose D.P. \& Claver M.A. 1997: Functional and numerical responses of the reduviid predator, Rhynocoris fuscipes Fab. (Heteroptera: Reduviidae) to cotton leafworm Spodoptera litura Fab. (Lepidoptera: Noctuidae). - J. Appl. Entomol. 121: $331-336$.

Ambrose D.P. \& Claver M.A. 2001: Prey preference of the predator Rhynocoris kumarii (Heteroptera: Reduviidae) to seven cotton insect pests. - J. Appl. Zool. Res. 12: 129-132.

Ambrose D.P. \& Rani M.R.S. 1991: Prey influence on the laboratory mass rearing of Rhinocoris kumarii Ambrose and Livingstone, a potential biological control agent (Insecta: Heteroptera: Reduviidae). - Mitt. Zool. Mus. Berl. 67: 339-349.

Ambrose D.P. \& Sahayaraj K. 1993: Predatory potential and stage preference of reduviid predator, Allaeocranum quadrisignatum (Reuter) on Dysdercus cingulatus Fab. - J. Biol. Contr. 7: $12-14$

Ambrose D.P. , Rajan P. , Jesu S. \& Micheal R.J. 2008: Functional response of Rhynocoris kumarii Ambrose and Livingstone and normal and Synergy-505 exposed Rhynocoris marginatus (Fab.) to larva of Euproctis fraterna (Moore). - Indian J. Entomol. 70: 206-216.

Ben-Dov Y., Miller D.R. \& Gibson G.A.P. 2009: ScaleNet: A Searchable Information System on Scale Insects. Available online at http://www.sel.barc.usda.gov/scalenet/scalenet.htm (accessed 8 August 2009).

Claver M.A. \& Ambrose D.P. 2001a: Evaluation of Rhynocoris kumarii Ambrose and Livingstone (Hemiptera: Reduviidae) as a potential predator of some lepidopteran pests of cotton. - J. Biol. Contr. 15: 15-20.

Claver M.A. \& Ambrose D.P. 2001b: Impact of augmentative release of Rhynocoris kumarii Ambrose and Livingstone (Heteroptera: Reduviidae) on Dysdercus cingulatus (Fabricius) (Hemiptera: Pyrrhocoridae) population and damage on cotton. - J. Biol. Contr. 15: 119-125.

Claver M.A. \& Ambrose D.P. 2002: Functional response of the predator, Rhynocoris fuscipes (Heteroptera: Reduviidae) to three pests of pigeon pea. - Shashpa 9: 47-51.

Claver M.A., Rajan K. \& Ambrose D.P. 1996: Impact of mass rearing in the postembryonic development of Rhynocoris kumarii Ambrose and Livingstone (Heteroptera: Reduviidae). In Ambrose D.P. (ed.): Biological and Cultural Control of Insect Pests, an Indian Scenario. Adeline, Tirunelveli, India, pp. 216-219.

Fantinou A.A., Perdikis D.C., Maselou D.A. \& Lambropoulos P.D. 2008: Prey killing without consumption: does Macrolophus pygmaeus show adaptive foraging behavior. - Biol. Contr. 47: 187-193.
Fantinou A.A., Perdikis D.C., Labropoulosa P.D. \& Maselou D.A. 2009: Preference and consumption of Macrolophus pygmaeus preying on mixed instar assemblages of Myzus persicae. - Biol. Contr. 51: 76-80.

Getty T. \& Pulliam H.R. 1991: Random prey detection with pause-travel search. - Am. Nat. 138: 1459-1477.

Hodgson C.J., Abbas G., Arif M.J., Saeed S. \& Karar H. 2008: Phenacoccus solenopsis Tinsley (Sternorrhyncha: Coccoidea: Pseudococcidae), a new invasive species attacking cotton in Pakistan and India, with a discussion on seasonal morphological variation. - Zootaxa 1913: 1-35.

Holling C.S. 1965: The functional response of predators to prey density and its role in mimicry and population regulation. Mem. Entomol. Soc. Can. 48: 3-60.

Murdoch W.W. \& OAten A. 1975: Predation and population stability. - Adv. Ecol. Res. 9: 1-131.

Nagrare V.S., Kranthi S., Biradar V.K., Zade N.N., SAngode V., Kakde G. , Shukla R.M., Shivare D. , Khadi B.M. \& KranTHI K.R. 2009: Widespread infestation of the exotic mealybug species, Phenacoccus solenopsis (Tinsley) (Hemiptera: Pseudococcidae), on cotton in India. - Bull. Entomol. Res. 99: 537-541.

Nagrare V.S., Kranthi S., Kumar R., DharaJothi B., Amutha M., Deshmukh A.J. , Bisane K.D. \& Kranthi K.R. 2011: Compendium of Cotton Mealybugs. Central Institute for Cotton Research, Nagpur, 42 pp. http://www.cicr.org.in/pdf/compendium_of_cotton_mealybugs.pdf

Rocha L. DA \& Redaelli L.R. 2004: Functional response of Cosmoclopius nigroannulatus (Hem.: Reduviidae) to different densities of Spartocera dentiventris (Hemiptera: Coreidae) nympha. - Braz. J. Biol. 64: 309-316.

SAHAYARAJ K. 1991: Bioecology, Ecophysiology and Ethology of Chosen Predatory Hemipterans and their Potential in Biological Control (Insecta: Heteroptera: Reduviidae). Ph.D. Thesis, Madurai Kamaraj University, Madurai, India, 303 pp.

SAHAYARAJ K. 2012: Hunter reduviids in pest management for plantation crops. In Thomas S. (ed.): Selected Beneficial and Harmful Insects of Indian Subcontinent. Lap Lambert Academic Publishing, Colne, pp. 58-69.

Sahayaraj K. \& Asha A. 2010: Biological control potential evaluation of Rhynocoris kumarii Ambrose and Livingstone on Aphis craccivora (Koch). —Indian J. Agric. Sci. 44: 281-287.

Sahayaraj K. \& Sivakumar K. 1995: Groundnut pest and pest stage preference of a reduviid predator Rhynocoris kumarii Ambrose and Livingstone (Heteroptera: Reduviidae). - Fresen. Environ. Bull. 4: 263-269.

Sahayaraj K., Kalidas S. \& Majesh T. 2012: Stage preference and functional response of Rhynocoris longifrons (Stål) (Hemiptera: Reduviidae) on three hemipteran cotton pests. - Brazil. Arch. Biol. Technol. 55: 733-740.

Solangi G.S., Lohar M.K., Abro G.H. \& Buriro A.S. 2012: Biology and release of exotic predator Cryptolaemus montrouzieri Mulsant on mealybug Phenacoccus solenopsis Tinsley at Tandojam. - Sarhad J. Agric. 28: 429-435.

Tanwar R.K, Jeyakumar P. \& Monga D. 2007: Mealybugs and their Management. Technical Bulletin 19, September, 2007. National Centre for Integrated Pest Management, LBS Building, Pusa Campus, New Delhi 110 012. http://www.ncipm.org. in/mealybugs/Bulletin-Mealybugs\%20(English).pdf (accessed 9 September 2014).

Vennila S., Deshmukh A.J., Pinjarkar D., Agarwal M., RamamURthy V.V., Joshi S., Kranthi K.R. \& Bambawale O.M. 2010: Biology of the mealybug, Phenacoccus solenopsis on cotton in the laboratory. - J. Insect Sci. 10:115, 9 pp. Available online: insectscience.org/10.115. 
WANG Y.P., Wu S.A. \& Zhang R.Z. 2009: Pest risk analysis of a new invasive pest, Phenacoccus solenopsis to China. - Chinese Bull. Entomol. 46: 101-106.

Zaka S.M., Saeed S., Bukhari S.A. \& Baksh E. 2006: Mealybug, Phenacoccus solenopsis (Homoptera: Pseudococcidae): a novel pest of cotton in Pakistan. In: Proceedings of 34th Pa- kistan (SAARC) Countries Science Conference, University of Veterinary and Animal Sciences, February 8-10, 2006, Lahore, Pakistan. p 32.

Received July 2, 2014; revised and accepted October 13, 2014 Prepublished online December 1, 2014 